\title{
HAWAII HURRICANE WAVE AND SURGE MODELING AND FAST FORECASTING
}

\author{
Jane McKee Smith ${ }^{1}$, Andrew B. Kennedy ${ }^{2}$, Joannes J. Westerink ${ }^{2}$, Alexandros A. Taflanidis ${ }^{2}$, \\ and Kwok Fai Cheung ${ }^{3}$
}

\begin{abstract}
The US Army Corps of Engineers' Surge and Wave Island Modeling Studies developed a fast forecasting system for hurricane waves and inundation in Hawaii. The system is based on coupled high-resolution, high-fidelity simulations of waves and surge applying the SWAN and ADCIRC numerical models on a 2D finite-element grid. Additionally, wave runup is simulated on high-resolution cross-shore transects using the Boussinesq-equation model BOUSS-1D. Approximately 1500 storms were simulated to cover the range of hurricane parameters of landfall location, track angle at landfall, central pressure, forward speed, and radius of maximum winds expected to impact Hawaii. To create a forecast system that is fast and robust, a moving least-squares response surface surrogate model was developed based on the high-fidelity model results. The surrogate model is approximately seven orders of magnitude faster than the high-fidelity simulations. The efficiency of the surrogate model allows both deterministic and probabilistic simulations in seconds to minutes on a personal computer.
\end{abstract}

Keywords: hurricanes; storm surge; inundation; Hawaii; ADCIRC; SWAN

\section{INTRODUCTION}

U.S. Pacific Island coasts and populations are extremely vulnerable to tropical cyclones. Typically, much of the island infrastructure is within the hazard zone and evacuation options are more limited than on the mainland. Islands have steep bathymetric slopes, large storm waves close to the shoreline, and fringing coral reefs. Powerful hurricanes raise water levels, which allow larger waves to propagate over the reefs and impact the island coastlines, resulting in coastal inundation, damage, and loss of life. In September 1992, Hurricane Iniki made landfall on the Island of Kauai as a Category 4 hurricane (63 m/s winds), causing nearly $\$ 2$ bill in damages. The steep bathymetry along island coasts limits the wind-driven surge, but large storm waves break directly on the reefs and induce large wavedriven surge (wave setup). The wave setup is approximately comparable to the combined surge due to the wind stress and the inverted barometer. Roughness on the reefs results in friction coefficients being approximately an order of magnitude larger than in other coastal areas. The reefs contribute to dissipation of the waves and reduced current velocities. Infragravity waves are excited over the shallow reefs, and these long waves force strong runup and intermittent inundation.

The US Army Corps of Engineers' Surge and Wave Island Modeling Studies (SWIMS) developed a fast forecasting system for hurricane inundation for the Hawaiian Islands. The system applies highfidelity, high-resolution wave, surge, and runup simulations to build a database of hurricane response that covers the range of hurricanes parameters expected to impact the islands. The response database is used to develop a surrogate model of waves and inundation based on response surface approximations.

\section{STORM SELECTION}

Hurricanes impacting Hawaii have been infrequent. Since 1950, only five hurricanes have caused significant damage in Hawaii:

- $\quad$ Hurricane Nina 1957 (passed west of Kauai)

- $\quad$ Hurricane Dot 1959 (made landfall on Kauai)

- $\quad$ Hurricane Iwa 1982 (passed west of Kauai)

- $\quad$ Hurricane Estelle 1986 (passed south of the Hawaiian Islands)

- Hurricane Iniki 1992 (made landfall on Kauai)

Despite the infrequency of hurricanes in Hawaii, the potential impacts are significant. If a Category 4 hurricane (peak wind speeds of 59-69 m/s) made landfall on Oahu, there would be severe damage to air and sea ports, island-wide power and communications outages, destruction of a large percentage of

\footnotetext{
${ }^{1}$ U.S. Army Engineer Research and Development Center, 3909 Halls Ferry Rd., Vicksburg, MS, 39180, USA.

${ }^{2}$ University of Notre Dame, Department of Civil and Environmental Engineering and Earth Sciences, 156 Fitzpatrick Hall, Notre Dame, IN, 46556, USA.

${ }^{3}$ University of Hawaii at Manoa, Department of Ocean and Resources Engineering, Holmes Hall 402, 2540 Dole Street, Honolulu, HI, 96822, USA.
} 
homes, and hundreds of thousands of people seeking shelter (Kenneth F. Gilbert, personal communication, September 2010).

Since the historical record for selecting potential storms is sparse, characteristic storm parameters and tracks were selected based on historical storms and input from the National Weather Service. A matrix of potential storms was built by varying five hurricane parameters over a range of likely values. The parameters are landfall location, track angle, central pressure, radius of maximum winds, and forward speed. Hurricanes impacting Hawaii transit from east to west and then curve (or re-curve) to the north. Figure 1 shows the five tracks selected for simulation, designated by the angle at landfall (120, 150, 180, 210, and 240 deg, measured clockwise from north). These tracks were shifted from east to west through the Hawaiian Islands to give 28 landfall locations (including "landfalls" between the islands). Central atmospheric pressures simulated were 940, 955, and $970 \mathrm{mb}$, roughly representing Category 2 to 4 hurricanes. Radii of maximum winds simulated were 30, 45, and $60 \mathrm{~km}$, and forward speeds were 3.9, 7.7, and $11.6 \mathrm{~m} / \mathrm{s}$. Not all combinations of parameters were considered, based on historical trends. Approximately 1500 storms were selected for modeling.

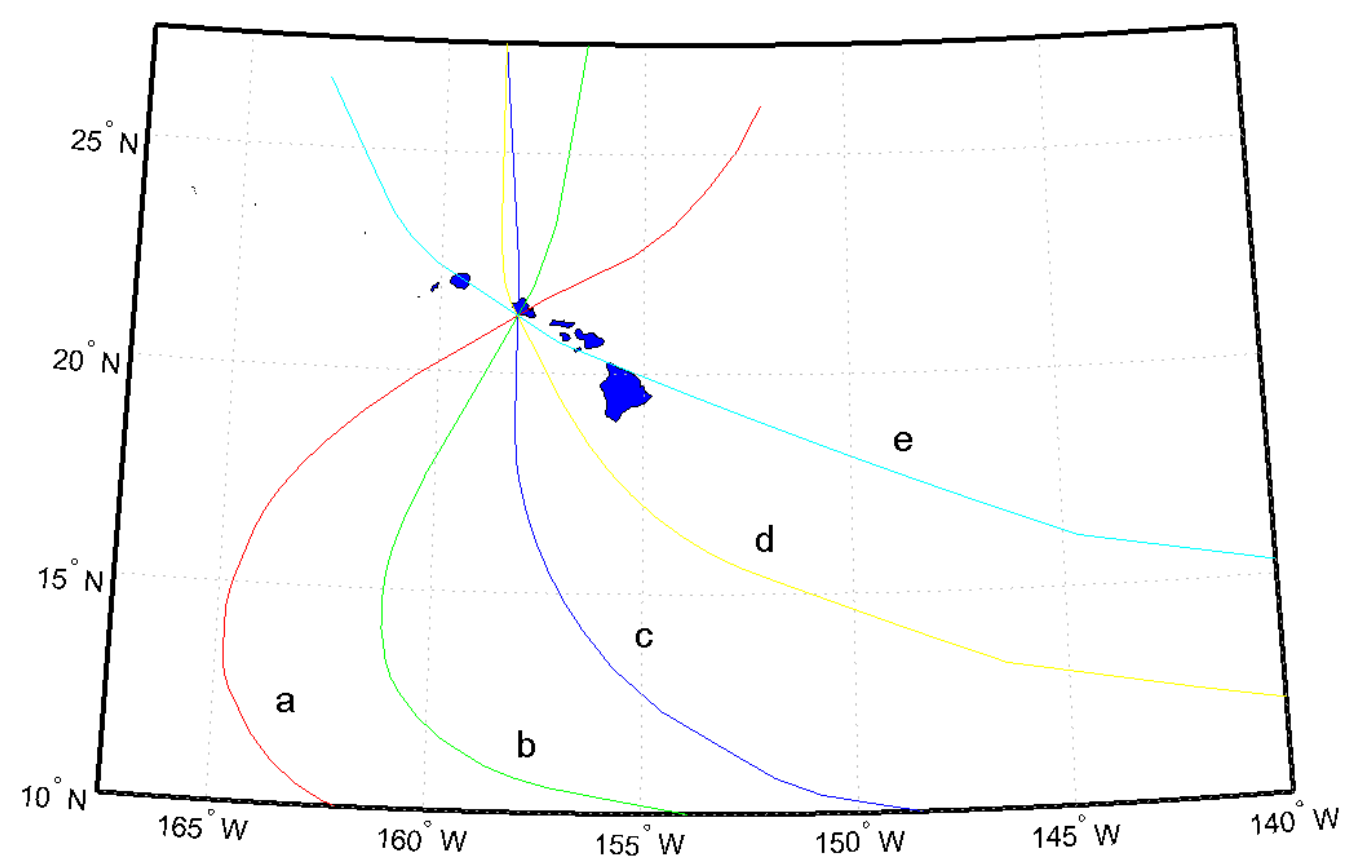

Figure 1. Representative hurricane tracks and angles of incidence. The axes are degrees latitude and longitude.

\section{HIGH-FIDELITY HYDRODYNAMIC MODELS}

Waves, storm surge, and runup are modeled for Hawaii using high-fidelity, high-resolution numerical models. For this study, the modeling is broken into two parts: tightly-coupled wave and surge modeling on a two-dimensional, finite-element grid and runup modeling on one-dimensional, shore-perpendicular transects. The runup is driven with the waves and water levels generated from the coupled wave and surge models.

\section{Waves and Surge}

To accurately calculate waves and surge in Hawaii, it is critical to resolve the fringing reefs, wave breaking zones, and the channels in the nearshore region. Additionally, to include wave generation as hurricanes track toward Hawaii, the mesh domain must be sufficiently large to cover the generation region. To include both high resolution and a large domain, a finite-element approach was adopted. The computational grid extends from the equator to 35 deg north and from 139 to 169 degrees west. Bathymetry and topography used to generate the mesh were extracted from several datasets, including bathymetric and topographic lidar, shipboard multi-beam bathymetry, and National Oceanographic and Atmospheric Administration (NOAA) bathymetric databases. The U.S. Geological Survey National Gap Analysis Program (GAP) landcover database was used to specify Manning $\mathrm{n}$ bottom friction coefficients based on vegetation cover or land use type (Bunya et al. 2010). Nearshore reefs were 
identified by hand where possible and given a large frictional value of $n=0.22$, and oceanic areas with no other classification were specified to have a value of $n=0.02$. To reduce the overall computational effort, two meshes were developed, both of which covered the same region, but one mesh has high resolution on Oahu and Kauai and the other has high resolution on Maui and the Big Island. Mesh resolution varied from $5000 \mathrm{~m}$ in deep water to $30 \mathrm{~m}$ in the nearshore and upland areas. The mesh resolution and domain for the Oahu-Kauai grid is shown in Figure 2. The grids contain approximately 3 million elements and 1.6 million nodes.

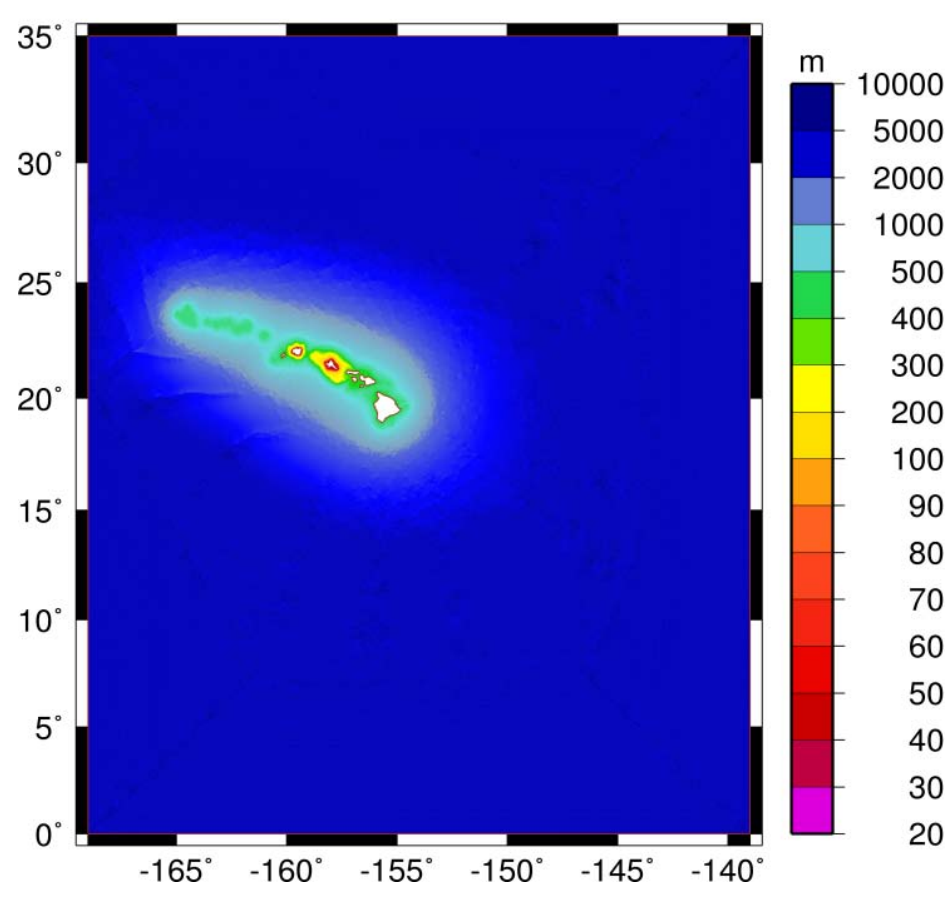

Figure 2. Grid resolution and grid domain for the Oahu-Kauai computational grid. The axes are degrees latitude and longitude.

The storm surge and waves were modeled with the unstructured, phase-averaged wave model SWAN (Zijlema 2010) tightly coupled to the ADCIRC circulation model (Luettich and Westerink 2004). Both models were applied on the same unstructured mesh. The models were driven with wind and pressure fields generated with a planetary boundary layer model (Thompson and Cardone 1996), applying a Garratt formulation for wind drag. SWAN was applied with 72 directional and 45 frequency bins. The standard SWAN third-generation physics were applied with Cavaleri and Malanotte-Rizzoli (1981) wave growth and shallow water triads. The ADCIRC time step was $1 \mathrm{~s}$, the SWAN time step was $600 \mathrm{~s}$, and two-way coupling was performed after each SWAN time step. The model coupling follows applications in the Gulf of Mexcio described by Dietrich et al. (2011) and Bunya et al. (2010). Radiation stresses were computed by SWAN and passed to ADCIRC to force nearshore wave setup and currents, and water levels and currents were computed by ADCIRC and passed to SWAN. Simulations were run at a constant high tide of $0.4 \mathrm{~m}$ Mean Tide Level (MTL). Tidal variations in space and time were neglected. The inundation represented by ADCIRC is the still-water inundation, which is an average water level over approximately $10 \mathrm{~min}$ (averaged over individual waves). Coupled SWAN and ADCIRC simulations require approximately 2000 CPU hours on a high-performance computer for each storm. Kennedy et al. (2012) provide model validation for water levels due to tides and for waves and water levels induced by Hurricane Iniki on Kauai. Figures 3 and 4 show examples of the maximum water levels and maximum significant wave heights, respectively, for a storm with a central pressure of $940 \mathrm{mb}$, radius of maximum winds of $60 \mathrm{~km}$, and forward speed of $3.6 \mathrm{~m} / \mathrm{s}$ making landfall on Oahu at an angle of $240 \mathrm{deg}$. The hurricane track is shown with the thick black line. An atlas of maximum water levels and wave heights was developed with graphics from each of the simulations run for the study, including a wide view with all the islands and detailed views of the impacted islands. 


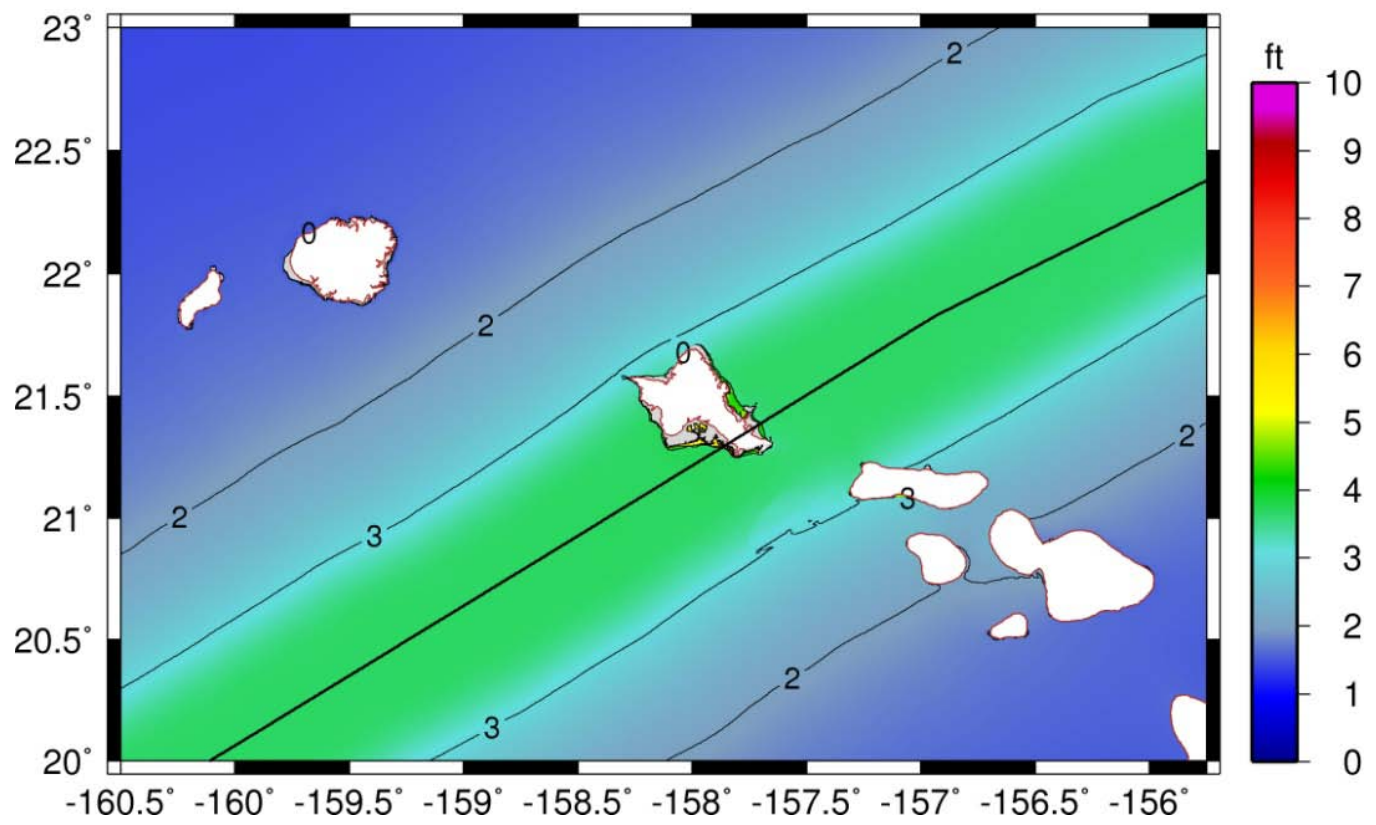

Figure 3. Maximum water levels ( $\mathrm{ft}$ ) for a storm with a central pressure of $940 \mathrm{mb}$, radius of maximum winds of $60 \mathrm{~km}$, and forward speed of $3.6 \mathrm{~m} / \mathrm{s}$ making landfall on Oahu with an angle of $240 \mathrm{deg}$. The axes are degrees latitude and longitude.

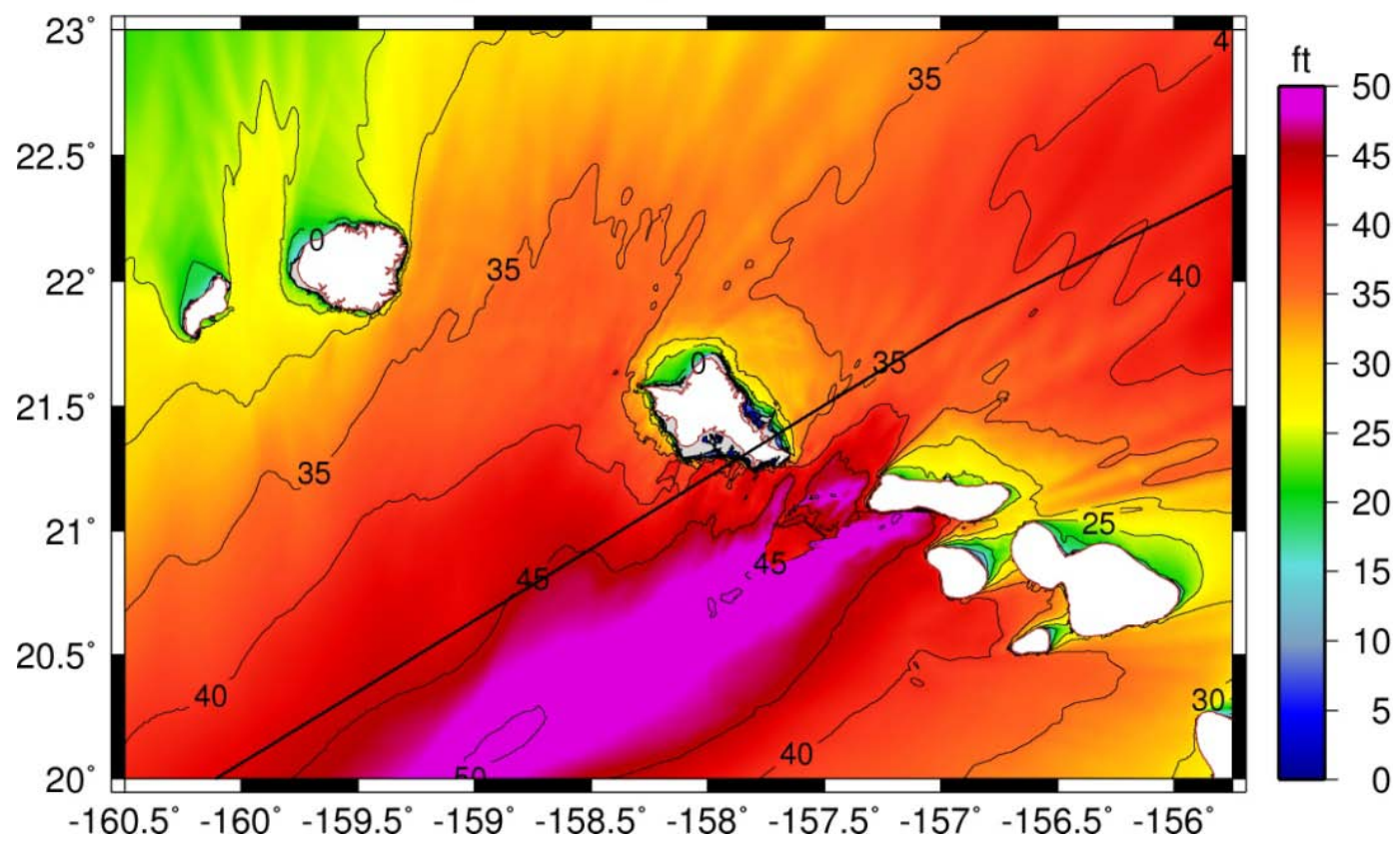

Figure 4. Maximum significant wave height (ft) for a storm with a central pressure of $940 \mathrm{mb}$, radius of maximum winds of $60 \mathrm{~km}$, and forward speed of $3.6 \mathrm{~m} / \mathrm{s}$ making landfall on Oahu with an angle of $240 \mathrm{deg}$. The axes are degrees latitude and longitude. 


\section{Runup}

In addition to the still-water inundation, individual wave crests and slowly varying wave groups (infragravity waves) can penetrate much further inland, beyond the still-water inundation. The wave runup is defined as the maximum vertical excursion of the waves relative to the pre-storm mean water level. The horizontal inundation caused by wave runup is referred to as runup inundation. The runup can be particularly significant in the Hawaiian Islands, where large waves propagate close to shore due to the steep offshore bathymetry and lack of a continential shelf. Inland wave penetration caused significant damage on Kauai during Hurricane Iniki (inundation penetration hundreds of meters horizontally and runup several meters vertically). Wave runup was modeled with a Boussinesqequation model that resolves individual waves and includes the nonlinear processes that drive generation of infragravity waves. Boussinesq models are more computationally intensive than the coupled phase-averaged wave and surge models, so running a two-dimensional Boussinesq model was not practical for this application. Instead, the one-dimensional Boussinesq model BOUSS-1D (Demirbilek and Nwogu 2007) was applied on one-dimensional cross-shore transects. The cross-shore resolution of the transect grids was $5 \mathrm{~m}$, and the transects were initiated at a depth of $40 \mathrm{~m}$ or $2 \mathrm{~km}$ offshore (whichever was closer to the shoreline). Figure 5 shows an example of a bathymetry transect, the input water surface elevation and the output runup inundation distance and elevation for an input significant wave height of $8.8 \mathrm{~m}$ and water level of $1.4 \mathrm{~m}$ (tide plus surge). The maximum resulting runup is $6 \mathrm{~m}$ and maximum inundation is $130 \mathrm{~m}$. The alongshore transect spacing was approximately $500 \mathrm{~m}$. The BOUSS-1D modeling does not account for buildings or dense vegetation (a bare earth assumption is made), so results are conservative in urban or densely vegetated areas. Peak waves and water levels from the ADCIRC-SWAN simulations were used as offshore boundary conditions for BOUSS-1D. The model output is the maximum runup and inundation for each transect. The number of transects applied for each island was 300-800. Hundreds of thousands of BOUSS-1D model runs were performed.
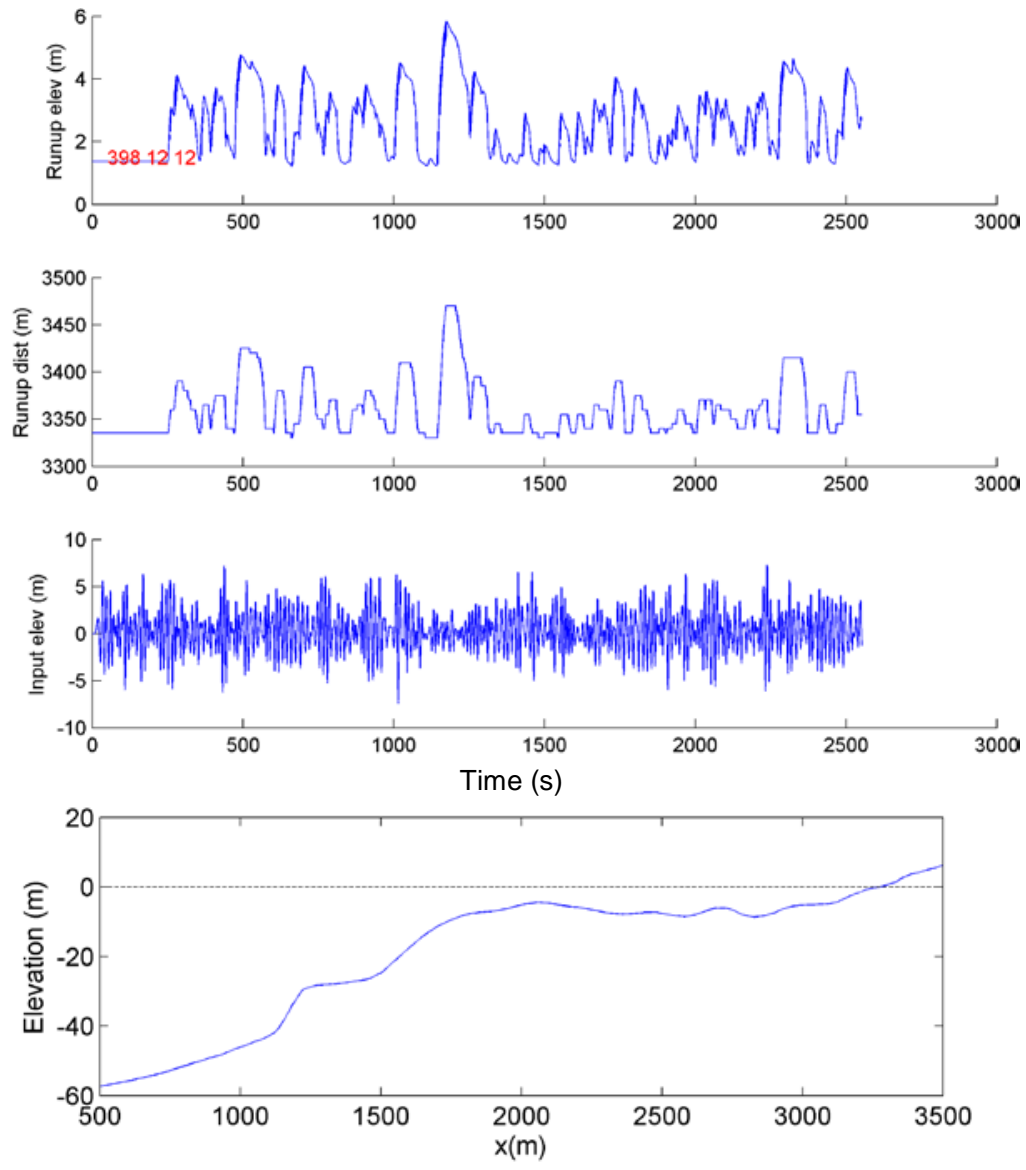

Figure 5. BOUSS-1D bathymetry transect and example input water surface elevation for significant wave height of $8.8 \mathrm{~m}$ and water level of $1.4 \mathrm{~m}$ and output inundation distance and runup elevation. 


\section{PROBABILISTIC HURRICANE PREDICTION}

After the suite of storms was simulated, the scenarios were used to create a surrogate model of storm response (maximum still-water inundation, runup inundation, and wave height). The surrogate model inputs are the five hurricane parameters of landfall location, angle at landfall, central pressure, forward speed, and radius of maximum winds. The surrogate model is developed using quadratic basis functions and minimizing a weighted mean squared error over the high-resolution scenarios to evaluate the coefficients. Applying weights improves the efficiency of the approximation by giving higher influence to the high-fidelity scenarios with similar parameters (moving least squares response surface approximation). Surrogate model average mean errors for wave height and still-water level are approximately 3.5 and 7 percent, respectively (Taflanidis et al. 2012b). Figure 1 shows an example comparison of forecast maximum wave height using the high-fidelity models and the surrogate model (for a case not used to develop the surrogate model). The contours of maximum wave height are not identical, but show very good representation of the magnitudes and spatial variability of the maximum wave heights. Details of the surrogate model development are given by Taflanidis et al. (2012a and b).
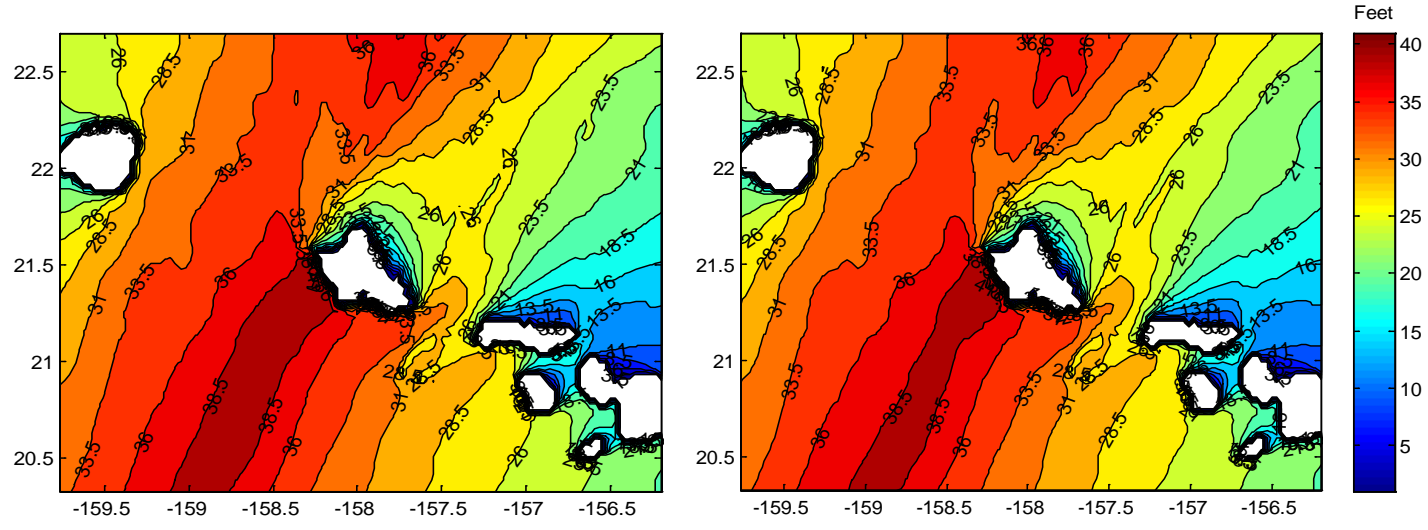

Figure 6. Maximum significant wave height forecast with high-fidelity model (left) and surrogate model (right). Axes are degrees latitude and longitude.

The great advantage of the surrogate model is that it is able to evaluate the maximum storm response at a cost that is more than seven orders of magnitude less than the high-fidelity models with comparable accuracy. The surrogate model executes in just a few seconds on a personal computer for a single storm simulation. The speed and simplicity of the surrogate model makes it ideal for fast storm inundation forecasting. The approach is robust because the high-fidelity model runs have been quality controlled prior to the construction of the surrogate model. The surrogate model can be run directly from National Weather Service hurricane forecasts.

Because the surrogate model is so fast, it can be run not only for a single storm, deterministic mode, but also in a probablistic mode. All hurricane forecasts contain errors, so emergency managers must consider not only the forecast track and intensity, but also likely variations in the storm forecast parameters. Running high-fidelity models in real time generally does not allow time for very many scenerios to be simulated. The probablistic mode of the surrogate model is established by estimating the errors in forecast parameters using a zero-mean Guassian distribution and estimating the standard deviation of the errors as a function of time to landfall. Uncertainty in the parameters decreases as the storm approaches landfall. The standard deviations used for probablistic modeling for 72 and 12 hrs from landfall are given in Table 1, and values between these times are estimated by linear interpolation. Probabilistic simulations are made with the surrogate model by randomly selecting the input parameters from the distribution and running one thousand simulations to evaluate the response (inundation or wave height) for a given exceedance. For example, the 10 percent exceedance wave height is the wave height exceeded 10 percent of the time given the storm variability and model errors. As a hurricane is far from landfall, emergency managers may focus on small exceedance values (i.e., 10 percent) to plan evacuations when there is still significant uncertainty in forecasts and apply larger exceedance values (i.e., 50 percent) or deterministic simulations when the storm is near landfall and the focus is on recovery. 


\begin{tabular}{|c|c|c|c|c|c|}
\hline \multicolumn{6}{|c|}{ Table 1. Standard deviations of hurricane parameters as a function of time to landfall. } \\
\hline \multirow{2}{*}{$\begin{array}{c}\text { Time to landfall } \\
\text { (hrs) }\end{array}$} & $\begin{array}{c}\text { Landfall location } \\
\text { (deg longitude) }\end{array}$ & $\begin{array}{c}\text { Track heading at } \\
\text { landfall (deg) }\end{array}$ & $\begin{array}{c}\text { Central pressure } \\
\text { (mb) }\end{array}$ & $\begin{array}{c}\text { Forward speed } \\
\text { (m/s) }\end{array}$ & $\begin{array}{c}\text { Radius of max } \\
\text { winds (km) }\end{array}$ \\
\hline 72 & 0.85 & 30 & 18 & 3.7 & 6 \\
\hline 12 & 0.14 & 5 & 3 & 0.5 & 1 \\
\hline
\end{tabular}

Figure 7 shows the SWIMS fast forecasting interface (Hakou version 4) with an input for a Category 4 hurricane landfalling at $21.3 \mathrm{deg} \mathrm{N}$ and $158 \mathrm{deg} \mathrm{W}$ (south central Oahu), with a track angle of 150 deg (from the south-southeast), central pressure of $940 \mathrm{mb}$, forward speed of $10.3 \mathrm{~m} / \mathrm{s}$, and a radius of maximum winds of $20 \mathrm{~km}$. The interface includes the parameter inputs, time or distance to landfall, and plot of the track. The instruction window in the upper left guides users through the calculation and plotting steps. Figure 8 provides example forecasts output for the 10 percent exceedance maximum significant wave height for this forecast hurricane 72 and 24 hrs before landfall. The deterministic maximum significant wave height is shown in Figure 9. These plots show that as the hurricane approaches landfall and the forecast errors are reduced, the magnitude and spread of 10 percent exceedance maximum wave heights are reduced. By 24 hrs before landfall, the forecast maximum wave heights are similar to the deterministic forecast, but slightly higher (note the change in scale between Figures 8 and 9). For this example, the hurricane parameters were unchanged for the 72, 24, and deterministic forecasts, but typically, the forecast parameters would evolve, and the broad regions of large waves heights in the $72 \mathrm{hr}$ forecast reflect the uncertainty in the forecast parameters.

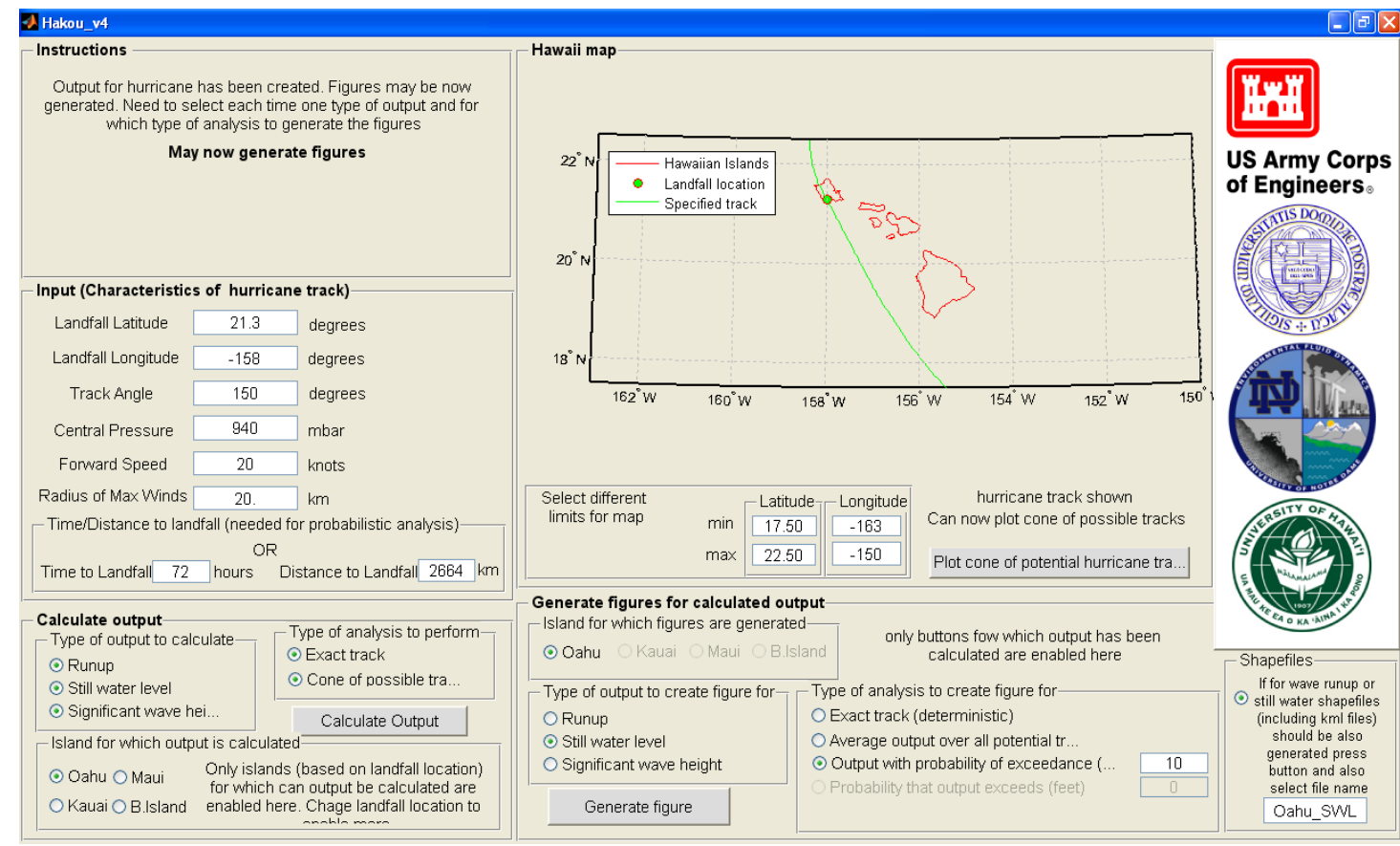

Figure 7. SWIMS interface showing track and landfall location for example category 4 storm striking the south central coast of Oahu. 

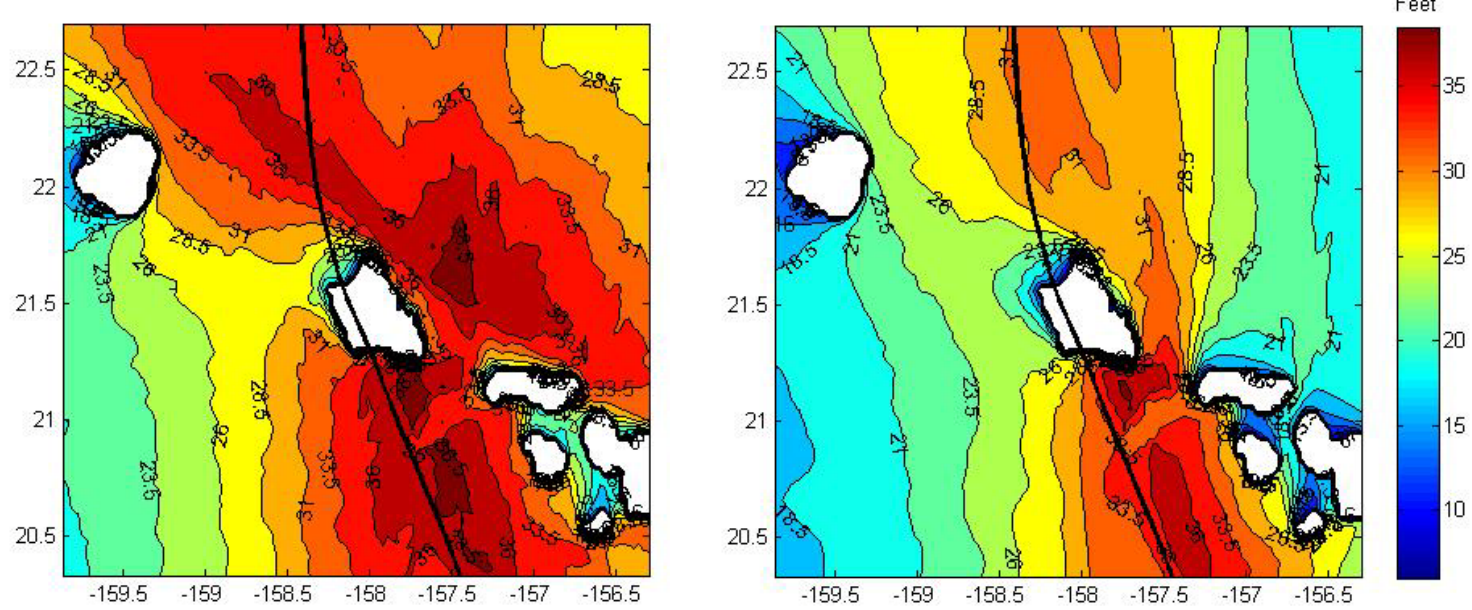

Figure 8. Ten-percent exceedance maximum significant wave height forecast for $72 \mathrm{hrs}$ before landfall (left) and $24 \mathrm{hrs}$ before landfall (right) for a category 4 storm making landfall on the south central coast of Oahu, Hawaii (land fall $21.3 \mathrm{deg} \mathrm{N}, 158 \mathrm{Deg} \mathrm{W}$, track angle of $150 \mathrm{deg}$, central pressure $940 \mathrm{mb}$, forward speed 10.3 $\mathrm{m} / \mathrm{s}$, radius of maximum winds $20 \mathrm{~km}$ ).

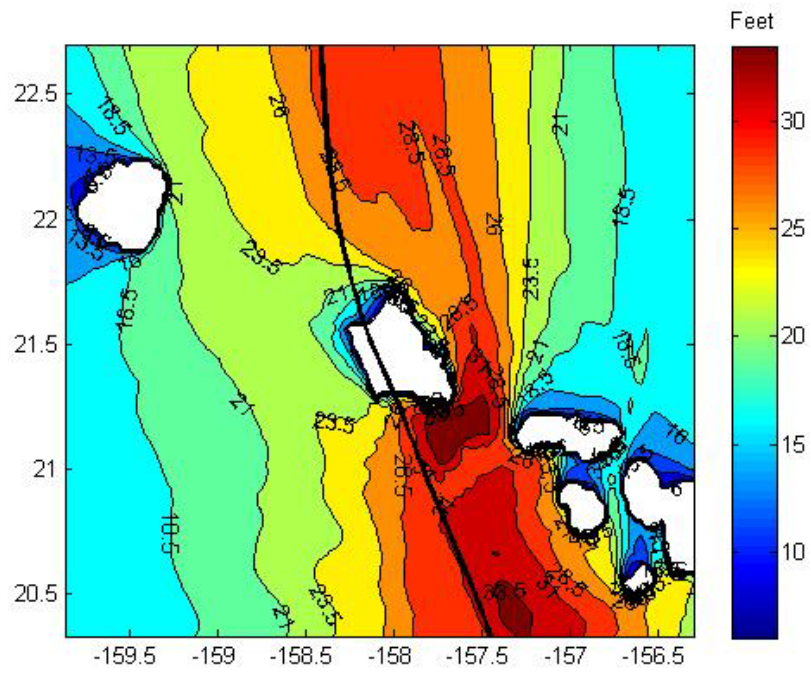

Figure 9. Deterministic maximum significant wave height forecast for a category 4 storm making landfall on the south central coast of Oahu, Hawaii (land fall $21.3 \mathrm{deg} \mathrm{N}, 158 \mathrm{Deg} \mathrm{W}$, track angle of $150 \mathrm{deg}$, central pressure $940 \mathrm{mb}$, forward speed $10.3 \mathrm{~m} / \mathrm{s}$, radius of maximum winds $20 \mathrm{~km}$ ).

Still-water and runup inundation lines are output as shape files that can be displayed in a Geographical Information System or Keyhole Markup Language (KML) files that can be displayed in Google Earth. These geo-referenced outputs allow emergency managers overlay inundation forecasts with critical infrastructure, such as evacuation shelters, transportation networks, and power plants. For the same hurricane forecast parameters used to generate wave heights in Figures 8 and 9, Figure 10 shows the maximum 10 percent exceedance still-water inundation lines for 72 and 24 hrs before landfall and the deterministic solution displayed in Google Earth for Waikiki and the Ala Wai Canal area on Oahu. Similar to the maximum wave height, the still-water inundation forecast at $72 \mathrm{hrs}$ before landfall, when forecast errors are larger, shows the largest extent of flooding, particularly north and east of the Ala Wai Canal. The forecast flooding extent is reduced for the 24-hr forecast and for the deterministic forecast, as expected. 


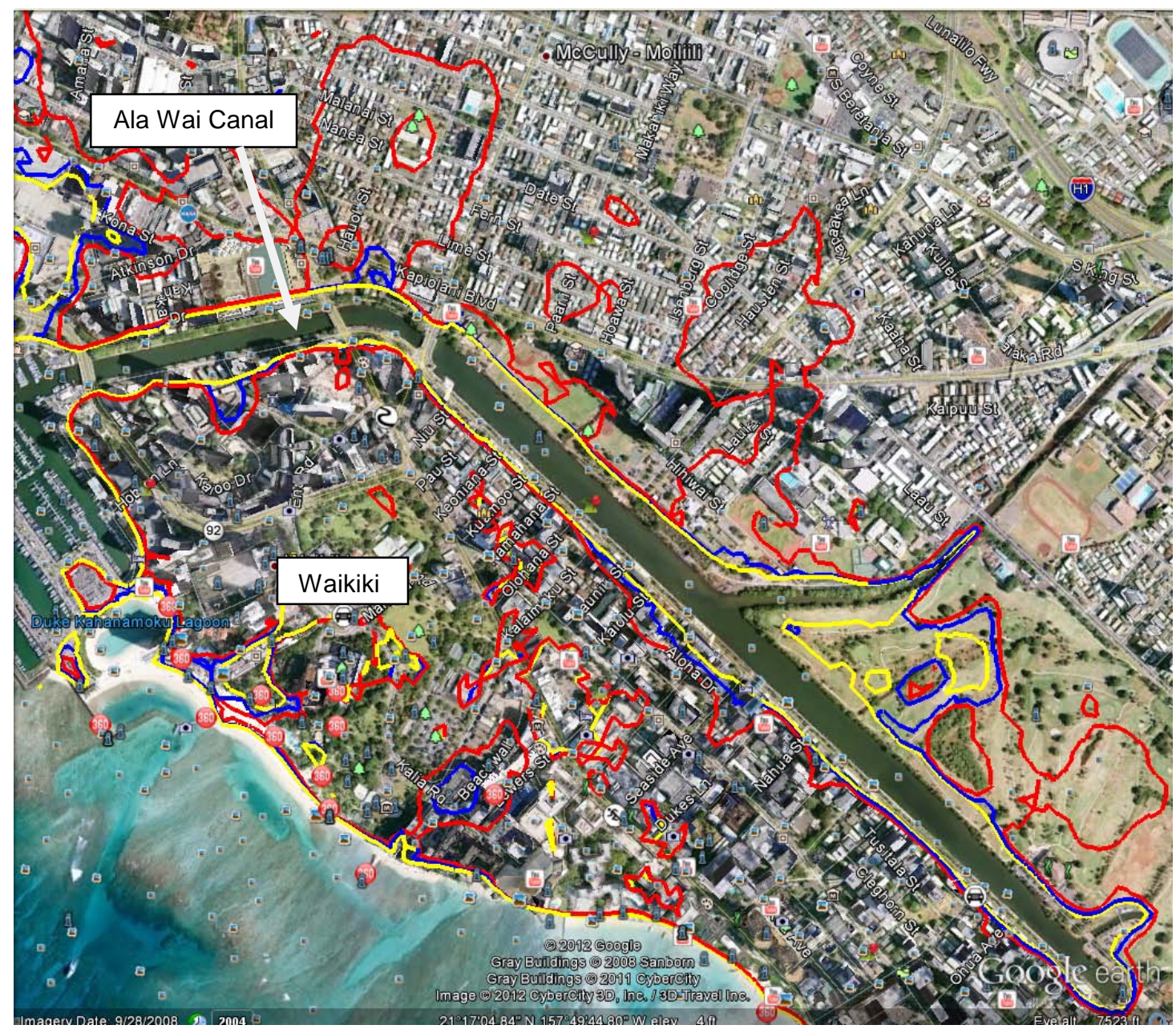

Figure 9. Ten percent exceedance maximum still-water inundation for Waikiki and the Ala Wai Canal forecast for $\mathbf{7 2} \mathrm{hrs}$ (red line) and $24 \mathrm{hrs}$ before landfall (blue line), and the deterministic forecast (yellow line) for Oahu, Hawaii, for a category 4 storm making landfall on the south central coast of Oahu, Hawaii (landfall $21.3 \mathrm{deg} N$, $158 \mathrm{Deg} \mathrm{W}$, track angle of $150 \mathrm{deg}$, central pressure $940 \mathrm{mb}$, forward speed $10.3 \mathrm{~m} / \mathrm{s}$, radius of maximum winds $20 \mathrm{~km}$ ).

\section{CONCLUSIONS}

The SWIMS fast forecasting system provides a framework for dynamic and fast evaluation of maximum wave heights and still-water and runup inundation for hurricanes approaching Hawaii. The fast forecasting system employs high-resolution, high-fidelity wave and surge models to simulate approximately 1500 hurricanes. These simulations were used to build a surrogate model of storm response, which is seven orders of magnitude faster than the high-fidelity models. Because of the speed of the surrogate model, it may be applied for deterministic assessment or probabilistic assessment, based on the error characteristics of the hurricane forecast parameters and model errors. The probabilistic assessment takes into account the reduction of forecast errors as hurricanes approach landfall. The SWIMS fast forecasting system takes advantage of both the accuracy of high-fidelity, high-resolution wave and surge modeling and the efficiency and robustness of surrogate modeling to produce deterministic and probabilistic forecasts of hurricanes waves and inundation in Hawaii.

\section{ACKNOWLEDGMENTS}

This work was funded by the Surge and Wave Island Modeling Studies, Coastal Ocean Data Systems Program, Engineer Research and Development Center, U.S. Army Corps of Engineers. The Program Manager is Mr. William Birkemeier and the Technical Director is Mr. William Curtis. Mr. Mark Hope and Mr. Mike Hartman, University of Notre Dame, assisted with hurricane simulations and data analysis. Permission to publish this work was granted by the Chief of Engineers, U.S. Army Corps of Engineers. 


\section{REFERENCES}

Bunya, S., J.C. Dietrich, J.J. Westerink, B.A. Ebersole, J.M. Smith, J.H. Atkinson, R. Jensen, D.T. Resio, R.A. Luettich, C. Dawson, V.J. Cardone, A.T. Cox, M.D. Powell, H.J. Westerink, and H.J. Roberts. 2010. A high-resolution coupled riverine flow, tide, wind, wind wave, and storm surge model for southern Louisiana and Mississippi. Part I: Model development and validation. Monthly Weather Review, 138, 345-377.

Cavaleri, L., P. Malanotte-Rizzoli. 1981. Wind wave prediction in shallow water: theory and applications. J. Geophysical Research, C11, 10961-10973.

Demirbilek, Z., and O. Nwogu. 2007. Boussinesq modeling of wave propagation and runup over fringing coral reefs, ERDC/CHL TR-07-12, CHL, ERDC, Vicksburg, MS.

Dietrich, J. C., S. Bunya, J. J. Westerink, B. A. Ebersole, J. M. Smith, J. H. Atkinson, R. Jensen, D. T. Resio, R. A. Luettich, C. Dawson, V. J. Cardone, A. T. Cox, M. D. Powell, H. J. Westerink and H. J. Roberts 2010. A High Resolution Coupled Riverine Flow, Tide, Wind, Wind Wave and Storm Surge Model for Southern Louisiana and Mississippi: Part II - Synoptic Description and Analyses of Hurricanes Katrina and Rita. Monthly Weather Review, 138(2), 378-404.

Kennedy, A. B., J.J. Westerink, J. Smith, A.A. Taflanidis, M. Hope, M. Hartman, S. Tanaka, H. Westerink, K. F. Cheung, T. Smith, M. Hamman, M. Minamide, and A. Ota 2012. Tropical cyclone inundation potential on the Hawaiian islands of Oahu and Kauai. Ocean Modelling, 52-53, 54-68.

Luettich, R.A., and J.J. Westerink. 2004. Formulation and numerical implementation of the 2D/3D ADCIRC finite element model. http://adcirc.org/adcirc theory_2004_12_08.pdf

Taflanidis, A. A., A. B. Kennedy, J. J. Westerink, J. Smith, K. F. Cheung, M. Hope and S. Tanaka. 2012a. Rapid assessment of wave and surge risk during landfalling hurricanes; a probabilistic approach. Journal of Waterway, Port, Coastal and Ocean Engineering, (doi: 10.1061/(ASCE)WW.1943-5460.0000178).

Taflanidis, A., A. B. Kennedy, J. J. Westerink, J. Smith, T. Kijewski-Correa, and K. F. Cheung. 2012 b. Real-time assessment of wave and surge risk due to landfalling hurricanes. Proceedings, $33^{\text {rd }}$ International Conference on Coastal Engineering, this volume. Available at: http://journals.tdl.org/ICCE.

Thompson, E.F., and V. Cardone. 1996. Practical modeling of hurricane surface wind fields, Journal of Waterway, Port, Coastal and Ocean Engineering, 122 (4), 195-205.

Zijlema, M. 2010. Computation of wind-wave spectra in coastal waters with SWAN on unstructured grids, Coastal Engineering, 57, 267-277. 